\title{
Recombinant Interleukin-7
}

National Cancer Institute

\section{Source}

National Cancer Institute. Recombinant Interleukin-7. NCI Thesaurus. Code C592.

A recombinant protein which is chemically identical to or similar to endogenous interleukin-7 (IL-7) with hematopoietic and immunopotentiating properties. Produced by bone marrow, thymic stromal, and spleen cells, the cytokine interleukin-7 is a hematopoietic growth factor for progenitor B cells and T cells and stimulates proliferation and differentiation of mature T-cells and Natural Killer cells. ( $\mathrm{NCI05)}$ 